\title{
Prominence Effects on Hungarian Vowels: A Pilot Study
}

\author{
Alexandra Markón ${ }^{1,2}$, Márton Bartók $k^{1,2}$, Tekla Etelka Gráczi ${ }^{1,3}$, Andrea Deme ${ }^{1,2}$, \\ Tamás Gábor Csapó ${ }^{1,4}$ \\ ${ }^{1}$ MTA-ELTE “Lendület” Lingual Articulation Research Group, Budapest, Hungary \\ ${ }^{2}$ Eötvös Loránd University, Budapest, Hungary \\ ${ }^{3}$ Research Institute for Linguistics, Hungarian Academy of Sciences, Budapest, Hungary \\ ${ }^{4}$ Budapest University of Technology and Economics, Budapest, Hungary \\ marko.alexandra@btk.elte.hu, bartokmarton@gmail.com, graczi.tekla.etelka@nytud.mta.hu, \\ deme.andrea@btk.elte.hu, csapotetmit.bme.hu
}

\begin{abstract}
In the present study three members of the Hungarian vowel inventory $(/ \mathrm{i} /, / \mathrm{u} /, / \mathrm{p} /)$ were analysed as a function of prominence, with respect to gender and vowel quality. The theoretically most prominent (stressed and accented) and nonprominent (unstressed and unaccented) realizations were compared in terms of duration, $\mathrm{f}_{0}$, formants, and $\mathrm{OQ}$. The last two of these parameters were analysed systematically for the first time to the study of Hungarian.

On duration, there was a significant interaction between the effect of prominence and vowel quality: prominence led to longer duration for the vowels $/ \mathrm{p} /$ and $/ \mathrm{i} /$, but had no significant effect on $/ \mathrm{u} /$. On $\mathrm{f}_{0}$, we found a three-way interaction effect between prominence, vowel quality and gender, due to different patterns observed in males and females in the case of the vowel /i/. Formant analysis based on Euclidean distance from the vowel space centroid did not reveal any significant effect of prominence. The comparison of $F_{1}$ and $F_{2}$ values showed considerable differences between the prominence conditions in the case of the second formant of $/ \mathrm{p} /$. For OQ, we found different patterns for genders and vowels: prominence led to higher OQ values for women and lower OQ values for men. These between-gender differences were the most pronounced for the vowel $/ \mathrm{p} /$.
\end{abstract}

Index Terms: prominence, duration, $\mathrm{f}_{0}$, formants, $\mathrm{OQ}$, vowel quality, gender, Hungarian

\section{Introduction}

Prominence effects operate in various domains of speech. Linguistic prominence can be interpreted at several prosodic levels, depending on the particular model applied and on one's theoretical assumptions (see e.g., [1]). Languages vary in their marking of prominence both in terms of the phonetic features exploited and their contribution to lexical stress or sentence level accent. Several studies have examined articulatory or acoustic correlates of prominence in various languages, e.g., magnitude and velocity of opening and closing articulatory gestures, vowel formant patterns, spectral tilt, vowel intensity, pitch height or pitch change (see [1] for a review). However, the data are inconclusive to a large extent (for a review of studies on English that analysed the acoustic correlates of stress and accent, and found inconsistencies, see [2]).

At the lexical level, stress is highly predictable in Hungarian, assigned to the initial syllable of a content word. The existence of secondary stress has not been verified phonetically [3]; however, first syllable stress can be shifted to another syllable when stress is used to express semantic and/or pragmatic contrast. While content words bear first syllable stress, function words (e.g., definite and indefinite articles, postpositions, and conjunctions) appear as clitics, and do not bear stress, with the exception of contrastive, pragmatically motivated occurrences. In contrast with many other languages, Hungarian is not assumed to display any covariance between word stress and vowel quality, as suggested by e.g., [4]. However, an actual in-depth analysis of the interrelation of vowel quality and lexical stress and/or sentence level accent in Hungarian has not yet been performed.

Sentence level prominence can be realized in different ways in Hungarian. In broad focus sentences, each prosodic (content) word bears an accent. In the case of narrow focus, the focused constituent shows the highest prominence, while the ensuing elements are deaccented [5]. Narrow focus elements appear in specific syntactic positions, since Hungarian is an obligatory syntactic focus marking language. Due to the close interrelations between syntax and accent distribution, several studies have argued that prosodic means do not play an important role in prominence marking in Hungarian, which claim is also supported by evidence from both laboratory and spontaneous speech (see e.g., [5], [6]). However, some studies did find phonetic markers of focus prominence (see [7] and references), such as higher fo peaks and steeper $f_{0}$ fall on the narrow focussed element.

With both lexical and sentence levels included, four degrees of prominence can be discerned in Hungarian:

1. Initial syllable of a word in a narrow focus (preverbal focus) position, bearing both lexical stress and sentence level accent.

2. Initial syllable of a content/prosodic word in broad focus position, bearing lexical stress only.

3. Initial syllable of a verb in a verbal modifier + verb structure (forming a single prosodic word) in prohibitive sentences (with nehogy), when the first syllable of the verb bears sentence level accent, but it is not stressed (word stress is assigned to the first syllable of the verbal modifier; for further details see [8]).

4. Non-initial syllables of content words and syllables of clitics (except for contrastive accent) bear neither word stress nor sentence level accent.

The four degrees of prominence are summarized in Table 1. with the enlisted characteristics. All four types are also 
illustrated with an example, in which the syllables at hand are capitalized.

Table 1: Degrees of prominence.

\begin{tabular}{|c|c|c|l|}
\hline Degree & $\begin{array}{c}\text { Word } \\
\text { stress }\end{array}$ & $\begin{array}{c}\text { Sentence } \\
\text { level } \\
\text { accent }\end{array}$ & \multicolumn{1}{|c|}{ Example } \\
\hline 1 & + & + & $\begin{array}{l}\text { MArit kérdezte meg. } \\
\text { 'He asked Mary' }\end{array}$ \\
\hline 2 & + & - & $\begin{array}{l}\text { Megkérdezte MArit. } \\
\text { 'He asked Mary' }\end{array}$ \\
\hline 3 & - & + & $\begin{array}{l}\text { Nehogy megKËRdezze Marit! } \\
\text { 'He should not ask Mary' }\end{array}$ \\
\hline 4 & - & - & $\begin{array}{l}\text { MaRIT kérDEZTE MEG. } \\
\text { 'He asked Mary' }\end{array}$ \\
\hline
\end{tabular}

The most recent acoustic analysis of prominence in Hungarian is found in [8]. The authors' aim was to tease apart lexical stress and sentence level accent by performing a contrastive analysis of Hungarian and German prominence marking. The target vowel was measured in stressed vs. unstressed and accented vs. unaccented conditions in terms of duration, intensity, spectral balance (calculated by subtracting the vowel's sound pressure level from the level detected at high frequencies) and fo maximum (12 participants, 2 repetitions, target vowel: /o/). Two findings of this study are especially relevant for our present topic. Firstly, that duration played a role in expressing both stress and accent; and secondly, that only sentence level accent had an effect on intensity, spectral balance and $\mathrm{f}_{0}$.

Although vowel duration was analysed with respect to the level of prominence in Hungarian, possible vowel quality differences as a function of prominence have not been analysed systematically in Hungarian either, since, to the authors' knowledge, the apparent consensus that vowel quality is not expected to co-vary with lexical stress and/or sentence level accent is not supported by verifiable empirical evidence. Additionally, apart from a few earlier studies (see a review in [10]), whose methodological solutions were largely inexplicit, formant data have also not been analysed reliably.

Although various studies have been devoted to finding phonetic correlates of prominence in Hungarian, most research considered only the acoustic domain. Fónagy, in his wellknown investigations of articulation, defined prominence (in general) based on the higher activity of the internal intercostal muscles [9]. In this monography he also remarks on certain results that support his claims on the interrelation of articulatory activity (or vocal effort) observed at the level of the larynx and linguistic prominence (done by electroglottography), but unfortunately, further details of the research (including its findings) are not documented. Nevertheless, ever since the fifties, no studies addressed the articulatory implementation of prominence in Hungarian, in any respect.

Among glottal source parameters, the open quotient (henceforward OQ) is of considerable interest, since it has been reported to be related to voice quality [11]. OQ is defined as the ratio of the glottal open time over the fundamental period [11]. In an earlier study, based on five tense, and five lax German vowels read by five male and five female participants, [12] found that $\mathrm{OQ}$ data differed in terms of tenseness and stress, and that stress had an effect which interacted with gender: OQ values were found to be $7 \%$ higher for stressed vowels in females, but there was no difference found between the stress conditions in males. OQ was found to be the most reliable and consistent correlate of word stress by [13], who showed that word stress leads to a $2.5 \%$ decrease in the OQ, while focal accent did not affect it. In this study, the speech material (recorded with seven male speakers of German) consisted of one target vowel, /e:/, (in le syllables), which varied on two levels of focal accent and word stress, resulting in four different combinations (similarly to Table 1). In sum, based the above studies, the effect of the four possible degrees of prominence on the $\mathrm{OQ}$ parameter are yet inconclusive.

In the present pilot study we compared Hungarian vowels produced in syllables of the (theoretically) highest degree of prominence (Degree 1) and those without any prominence (Degree 4), in order to explore, if prominence affects the values of (i) vowel duration, (ii) the first two formants, (iii) $f_{0}$, and (iv) OQ. Consequently, in the present study we analysed the combined effect of lexical stress and sentence level accent, and did not aim to disentangle their (possible) separate impact. Based on the previous results summarized above, we expected differences between the prominence conditions both in the acoustic and articulatory measures. Additionally, we also analysed the effect of gender. In this respect, due to the wellknown differences in $f_{0}$ range, the general voice quality differences between male and female speakers, and the results of [12], we hypothesized a main effect on $f_{0}$ and an interaction effect of gender and prominence on OQ. Vowel quality was also hypothesized to affect duration (due to the different intrinsic durations of close and open vowels), $\mathrm{OQ}$, and $\mathrm{f}_{0}$ (due to larynx height differences expected in close and open vowels).

Our secondary aim was to investigate vocal fold vibration directly in the study of prominence effects in Hungarian, by the use of electroglottography. Although a large number of EGG-studies have already been performed on other languages, Hungarian differs from these with regard to both its word stress (fixed initial syllable stress) and sentence level accent (obligatory syntactic focus marking) characteristics. Therefore, the EGG analysis of prominence effects in Hungarian may provide further insights into the impact prominence exerts on laryngeal articulation.

\section{Methods}

\subsection{Material}

Our pilot study was carried out using the corpus of an earlier study [14] from which we selected the target vowels in phonetically matched contexts uttered by 18 speakers (7 women and $11 \mathrm{men}$; their age ranging between 23 and 43 years; mean $=32.2 \mathrm{ys}, \mathrm{SD}=3.8 \mathrm{ys}$ ). None of the speakers had any speech or hearing deficits.

Three vowels were chosen for analysis: the front and close /i/, the back and close $/ \mathrm{u} /$, and the back and open $/ \mathrm{p} /$ (i.e., the feature backness co-varied with lip rounding). The target vowels were analysed in the two prominence conditions: Degree 1, Degree 4 (see Table 1). The syllables containing the target vowels (marked bold below) were embedded into carrier sentences as follows (the numbers in lower indexes indicate degrees of prominence):

/p/1 Aha. Értem. 'Okay. I see.'

/p/4 A herendi porcelánnal tálalt... 'She used the herendi china for serving...' 
/i/1 Kihív. 'He dares you.'

/i/4 Valaki hireket hozott. 'Someone brought news.'

/u/1 Puhul a nö... 'The lady is getting less strict...'

/u/4 A lapu hullámokban takarja el az ösvényt... 'The burdock covers the pathway in waves...'

The stimuli were recorded three times in a randomized order by SpeechRecorder [15] (in the original corpus).

\subsection{Methods}

The speech and electroglottograph signals were recorded with an EGG D-200 (produced by Laryngograph Ltd) and an omnidirectional condenser tie clip microphone at $44.1 \mathrm{kHz}$ sampling rate and 16 bit in a sound treated room.

The annotation of the speech sounds was carried out in Praat [16]. We measured the following parameters on the target vowels: (i) the duration of the vowel; (ii) the mean value of $F_{1}$ and $F_{2}$ measured on the middle $50 \mathrm{~ms}$ of the vowel; (iii) $f_{0}$, and (iv) the mean OQ for all periods within the vowels, calculated from the EGG signal.

Formant frequencies were measured in Praat and standardized using $z$-transformation [17] for visualization using the phonR package [18]. In addition to $F_{1}$ and $F_{2}$, the Euclidean distance $(|\mathrm{d}|)$ between the centroid of the vowel space and each vowel [19] was also calculated and used as a dependent variable.

EGG signals were semi-automatically analysed using Praatdet [20], a Praat script implementing Peakdet [21] in the Praat scripting language using autocorrelation [22] for peak detection. The range of $f_{0}$ was set to $70-250 \mathrm{~Hz}$ for males and $100-350 \mathrm{~Hz}$ for females. Opening and closing instants of the glottal period were determined with a hybrid method [23], which defines the closing instant at the positive peak of the first derivative of the EGG signal (dEGG), whereas glottal opening is defined relative to the maximum of the EGG signal, using a threshold of $3 / 7$. OQ is then calculated by dividing the length of the open phase (time difference between opening and closing instant) by the length of the entire glottal period (defined as the time difference between two consecutive positive dEGG peaks). Both the EGG and dEGG signals were smoothed with moving average filter, using a smoothing step of 10 .

\subsection{Statistical analyses}

Due to mispronunciation, two male speakers'/p/-realizations, and one other male speaker's /u/-realizations had to be eliminated from the analysis.

We used the lme4 [24] package in $\mathrm{R}$ [25] to perform a linear mixed effects analysis of the effect of prominence, vowel quality, and gender (as fixed effects) on duration, $\mathrm{F}_{1}$, $\mathrm{F}_{2},|\mathrm{~d}|, \mathrm{f}_{0}$, and $\mathrm{OQ}$ values. In these models, we also included random intercepts for subjects, and random slopes by subject for the effect of prominence. Assumptions of homoscedasticity or normality were tested by visual inspection of residual plots. $P$-values were obtained via the Satterthwaite approximation. Pairwise comparisons were carried out with Tukey's post hoc tests.

\section{Results}

The mean and standard deviation of the values of all the measured dependent variables are shown as a function of gender and vowel quality in Table 2 . The statistical analysis of the data is presented in the following subsections.
Table 2: Results for the measured dependent variables as a function of gender and degree of prominence (mean $\pm 1 S D)$.

\begin{tabular}{|c|c|c|c|c|c|}
\hline & $\begin{array}{c}\text { Duration } \\
(\mathbf{m s})\end{array}$ & $\begin{array}{c}\mathbf{F}_{\mathbf{1}} \\
(\mathbf{H z})\end{array}$ & $\begin{array}{c}\mathbf{F}_{\mathbf{2}} \\
(\mathbf{H z})\end{array}$ & $\begin{array}{c}\mathbf{f}_{\mathbf{0}} \\
(\mathbf{H z})\end{array}$ & OQ \\
\hline \multicolumn{7}{|c|}{ Female speakers } \\
\hline$/ \mathbf{v} / \mathbf{4}$ & $77 \pm 27$ & $774 \pm 123$ & $1198 \pm 137$ & $200 \pm 39$ & $0,62 \pm 0,07$ \\
\hline$/ \mathbf{p} / \mathbf{1}$ & $45 \pm 18$ & $807 \pm 121$ & $1394 \pm 220$ & $207 \pm 36$ & $0,61 \pm 0,08$ \\
\hline$/ \mathbf{i} / \mathbf{4}$ & $67 \pm 18$ & $390 \pm 63$ & $2024 \pm 589$ & $192 \pm 32$ & $0,58 \pm 0,06$ \\
\hline$/ \mathbf{i} / \mathbf{1}$ & $54 \pm 12$ & $400 \pm 61$ & $2108 \pm 597$ & $211 \pm 33$ & $0,59 \pm 0,06$ \\
\hline$/ \mathbf{u} / \mathbf{4}$ & $70 \pm 14$ & $430 \pm 45$ & $863 \pm 358$ & $241 \pm 54$ & $0,61 \pm 0,06$ \\
\hline$/ \mathbf{u} / \mathbf{1}$ & $73 \pm 17$ & $434 \pm 48$ & $882 \pm 354$ & $248 \pm 39$ & $0,60 \pm 0,05$ \\
\hline \multicolumn{7}{|c|}{ Male speakers } \\
\hline \multicolumn{7}{|c|}{10} & $83 \pm 23$ & $642 \pm 82$ & $1068 \pm 148$ & $118 \pm 17$ & $0,61 \pm 0,06$ \\
\hline$/ \mathbf{v} / \mathbf{1}$ & $57 \pm 20$ & $640 \pm 151$ & $1288 \pm 378$ & $124 \pm 18$ & $0,66 \pm 0,06$ \\
\hline$/ \mathbf{i} / \mathbf{4}$ & $78 \pm 15$ & $337 \pm 38$ & $2205 \pm 229$ & $129 \pm 23$ & $0,56 \pm 0,05$ \\
\hline$/ \mathbf{i} / \mathbf{1}$ & $61 \pm 13$ & $319 \pm 28$ & $2206 \pm 255$ & $125 \pm 20$ & $0,60 \pm 0,07$ \\
\hline$/ \mathbf{u} / \mathbf{4}$ & $75 \pm 14$ & $354 \pm 35$ & $863 \pm 313$ & $145 \pm 27$ & $0,58 \pm 0,05$ \\
\hline$/ \mathbf{u} / \mathbf{1}$ & $74 \pm 14$ & $376 \pm 51$ & $866 \pm 445$ & $162 \pm 25$ & $0,57 \pm 0,08$ \\
\hline
\end{tabular}

\subsection{Vowel duration}

There was a significant interaction between degree of prominence and vowel quality $(F(2,282.85)=25.015, p<$ $0.001)$ : while $/ \mathrm{p} /$ and $/ \mathrm{i} /$ were significantly $(p<0.001)$ longer if they bore prominence, $/ \mathrm{u} /$ showed no such effect. For $/ \mathrm{u} /$, durations measured in both prominence conditions were similar to the duration values measured in the Degree 1 condition for the other two of the vowels. With respect to duration, males and females showed similar patterns (see Figure 1).

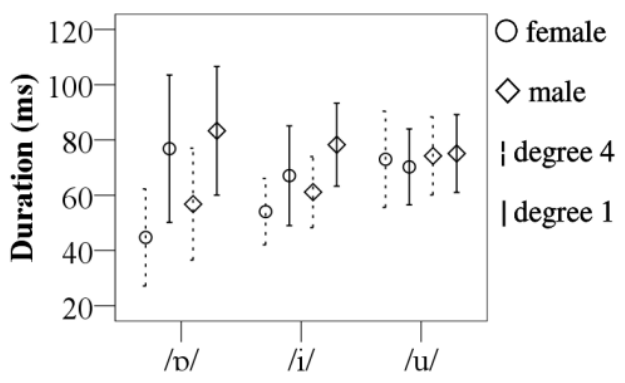

Figure 1: Vowel durations as a function of prominence and gender (mean $\pm 1 S D)$.

\subsection{Formant data}

No significant effect of prominence was observed on $\mathrm{F}_{1}$ ( $F(1$, 98.74) $=0.91, p=0.342)$. On $\mathrm{F}_{2}$, however, prominence showed a significant effect $(F(1,79.448)=4.88, p=0.030)$ : $\mathrm{F}_{2}$ was lower in vowels bearing prominence than in vowels realized without prominence.

Although prominence had a significant effect only on the values of the second formant, Figure 2 clearly indicates that with respect to the standardized values, the variability of both formants is considerably smaller in most of those cases, where the vowel bore a higher degree of prominence: $/ \mathrm{u} / 4\left(\mathrm{SD}_{\mathrm{F} 1}=\right.$ $\left.0.258, \mathrm{SD}_{\mathrm{F} 2}=0.623\right)$ vs. $/ \mathrm{u} / 1\left(\mathrm{SD}_{\mathrm{F} 1}=0.178, \mathrm{SD}_{\mathrm{F} 2}=0.468\right)$; $/ \mathrm{p} / 4\left(\mathrm{SDF}_{\mathrm{F} 1}=0.684, \mathrm{SDF}=0.614\right) \mathrm{vs} . / \mathrm{p} / 1\left(\mathrm{SDF}_{\mathrm{F} 1}=0.435, \mathrm{SDF} 2\right.$ $=0.384)$. This pattern emerged in both genders. 

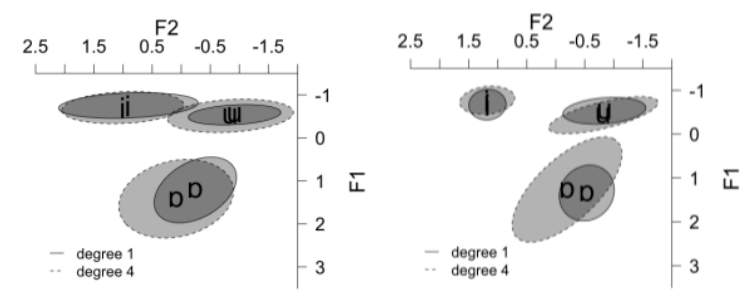

Figure 2: Standardised $F_{1} \times F_{2}$ space of the analysed vowels as a function of prominence and gender (left: females, right: males).

Euclidean distance from the vowel space centroid was not influenced by the degree of prominence significantly $(F(1$, 289.93) $=0.379, p=0.538$ ).

\subsection{Fundamental frequency}

For $\mathrm{f}_{0}$ (Figure 3 ) we found a significant three-way interaction between prominence, gender, and vowel quality $(F(2,281.14)$ $=5.162, p=0.006)$. Most probably, the interaction effect originates in the differences of the effect of prominence observable in /i/ for males and females: in males, /i/ had higher $\mathrm{f}_{0}$ in the Degree 1 prominence condition, but in females, the $f_{0}$ was lower.

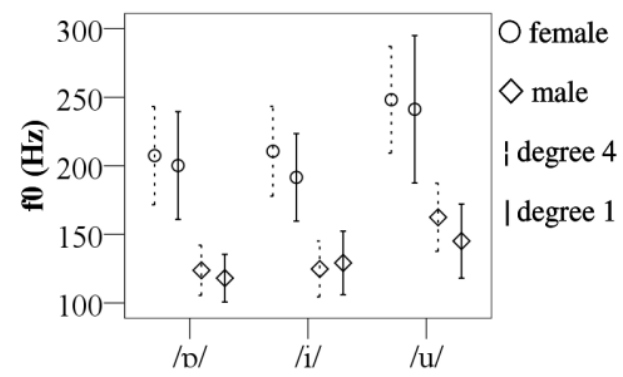

Figure 3: $F_{0}$ of the analysed vowels as a function of prominence and gender (mean $\pm 1 S D$ ).

\subsection{Open quotient}

Figure 4 shows the OQ-results by gender and vowel quality as a function of degree of prominence.

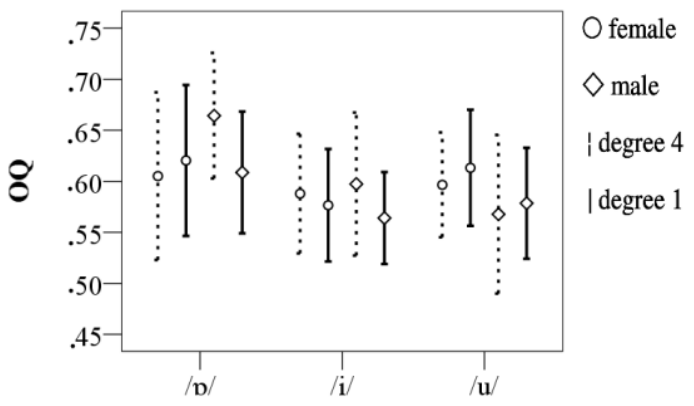

Figure 4: $O Q$ of the analysed vowels as a function of prominence and gender (mean $\pm 1 S D$ ).

As for OQ, interaction effects of prominence and gender $(F(1$, $17.96)=5.799, p=0.27$ ) and prominence and vowel quality $(F(2,281.69)=3.889, p=0.022)$ were found. These interactions may result from the effect of prominence, which differs as a function of gender in the case of the vowel $/ \mathrm{p} /$
Pairwise comparisons revealed that the $\mathrm{OQ}$ is significantly lower in the realizations of $/ \mathrm{w} /$ in the Degree 1 prominence condition in males, while in females, OQ was found to be higher (but in the latter case, no significant difference was found).

\section{Discussion and conclusions}

In the present study three members of the Hungarian vowel inventory $(/ \mathrm{i} /, / \mathrm{u} /, / \mathrm{p} /)$ were compared as a function of prominence regarding their duration, $\mathrm{f}_{0}, \mathrm{~F}_{1}$ and $\mathrm{F}_{2}$, and $\mathrm{OQ}$. $\mathrm{F}_{1}$, $F_{2}$, and $\mathrm{OQ}$ were analysed systematically for the first time in Hungarian, with respect to the effect of prominence.

Vowel durations were clearly affected by the degree of prominence: two vowels out of three, $/ \mathrm{p} /$ and $/ \mathrm{i} /$, were significantly longer in the Degree 1 condition (lexical stress + sentence level accent) than in the Degree 4 condition (no stress + no accent), while $/ \mathrm{u} /$ showed no such differences. This result is in line with those reported by [8]. With respect to $\mathrm{f}_{0}$, however, our findings differ from those published in [8], since in the present study prominence did not have an effect on fo. This inconsistency may reflect that $f_{0}$ is not as regularly affected by lexical stress and sentence level accent as vowel duration, but it also may stem from the methodological differences we applied in the two studies.

Analysis of $F_{1}$ and $F_{2}$ data was carried out in two ways: first we compared $F_{1}$ and $F_{2}$ values separately as a function of the degree of prominence, and then we calculated and compared Euclidean distances of vowel realizations from the vowel space centroid. While the latter comparison did not reveal a significant effect of prominence; the first comparison, showed considerable differences in the case of $F_{2}$ in $/ \mathrm{p} /$. The observed effect of prominence in the case of $/ \mathrm{p} /$ may have resulted from the difference in the linguistic function of $/ \mathrm{p} /$ in the Degree 1 and Degree 4 conditions, namely that in the Degree 4 condition / $\mathrm{p} /$ was represented by a definite article (in sentence initial position), as opposed to the $/ \mathrm{b} / \mathrm{s}$ in the Degree 1 condition and the rest of the target vowels, which were all represented by segments uttered as parts of longer words. Additionally, we also found that $F_{1}$ and $F_{2}$ show smaller variability in vowels bearing lexical stress and sentence level accent, than in those which are not stressed and accented.

Analysis of OQ showed that prominence interacts with gender in the case of $/ \mathrm{p} /$, that is, we found that in this specific vowel, the effect of prominence works in opposite directions in males and females. The interaction in itself is in line with the findings of [12], in which interaction of lexical stress and gender was found for OQ in German vowels. The interaction effect, however, is partly different in the two studies. In line with [12], in the present study we found that females produce the stressed and accented realizations of $/ \mathrm{p} /$ with higher OQ (although the magnitude of the difference between the conditions was considerably smaller in our data than in the German data). Unlike [12], however, we also found that in males the OQ was lower in the stressed and accented condition than in the no stress and no accent condition.

In conclusion, in agreement with earlier studies, we corroborated that vowel duration is most probably an acoustic cue of prominence in Hungarian. In our study, however, the prominence marking role of further parameters was not confirmed. The present results raise the question if $\mathrm{f}_{0}$ really plays a role in accent marking in Hungarian. We also suggest that OQ deserves further investigation with respect to the combined effect of prominence, vowel quality, and gender. 


\section{References}

[1] J. Fletcher, "The Prosody of Speech: Timing and Rhythm" in W. J. Hardcastle, J. Laver and F. E. Gibbon (eds.) The Handbook of Phonetic Sciences: Second edition. pp. 521-602, Oxford: Blackwell, 2010.

[2] R. Fuchs, "The Acoustic Correlates of Stress and Accent in English Content and Function Words" Proceedings of Speech Prosody, pp. 435-439. 2016.

[3] S. Blaho and D. Szeredi, "Secondary Stress in Hungarian: (Morpho)-Syntactic, Not Metrical", in Proceedings of the 28th West Coast Conference on Formal Linguistics, Somerville, MA: Cascadilla Proceedings Project, pp. 51-59, 2011.

[4] M. Gósy, "Semleges magánhangzók a magyar beszédben", Magyar Nyelvör 121, pp. 9-19, 1997

[5] K. Mády and F. Kleber, "Variation of pitch accent patterns in Hungarian", Proceedings of Speech Prosody 2010. http://speechprosody2010.illinois.edu/papers/100924.pdf

[6] A. Markó "A magyar hangsúly realizációinak és észlelésének összefüggése felolvasásban és spontán beszédben", in A. Markó (ed.) Beszédtudomány: Az anyanyelv-elsajátitástól a zöngekezdési időig, Budapest: MTA and ELTE, 2012, pp. 277303.

[7] S. Genzel, S. Ishihara and B. Surányi, "The prosodic expression of focus, contrast and givenness: A production study of Hungarian”, Lingua 165, pp. 183-204, 2015.

[8] Á. Szalontai, P. Wagner, K. Mády and A. Windmann, "Teasing apart lexical stress and sentence accent in Hungarian and German", in: Tagungsband 12. Tagung Phonetik und Phonologie im deutschsprachigen Raum (P\&P 12). pp. 216219, 2016.

[9] I. Fónagy, „A hangsúlyról” ser. Nyelvtudományi Értekezések 18. Budapest: Akadémiai Kiadó, 1958.

[10] A. Vértes O. "A Magyar beszédhangok akusztikai elemzésének kérdései”" in K. Bolla (ed.) Fejezetek a magyar leíró hangtanból, Budapest: Akadémiai Kiadó, pp. 71-113, 1982.

[11] N. Henrich, C. d'Alessandro, B. Doval, and M. Castellengo, "Glottal open quotient in singing: Measurements and correlation with laryngeal mechanisms, vocal intensity, and fundamental frequency", Journal of the Acoustical Society of America 117 (3), pp. 1417-1430. 2005.

[12] K. Marasek, "Glottal correlates of the word stress and the tense/lax opposition in German" in Proceedings of the ICSLP, Vol. 96, pp. 1573-1576, 1996.

[13] Ch. Mooshammer "Acoustic and laryngographic measures of the laryngeal reflexes of linguistic prominence and vocal effort in German", J Acoust Soc Am. 127(2), pp. 1047-1058, 2010.

[14] A. Deme, M. Bartók, T. E. Gráczi, A. Markó, G. Varjasi and T. G. Csapó, Intervocalic voicing of the Hungarian $/ \mathrm{h} /$, poster presented at the $13^{\text {th }}$ International Conference on the Structure of Hungarian, Budapest, 29-30 June 2017.

[15] C. Draxler and K. Jänsch, "SpeechRecorder - a universal platform independent multi-channel audio recording software," in Proceedings of International Conference on Language Resources and Evaluation, Lisbon, pp. 559-562, 2004.

[16] P. Boersma and D. Weenink, "Praat: doing phonetics by computer", 2016. http://www.fon.hum.uva.nl/praat/

[17] B. M. Lobanov, "Classification of Russian vowels spoken by different speakers", The Journal of the Acoustical Society of America 49. (2), pp. 606-608, 1971.

[18] D. R. McCloy, phonR: tools for phoneticians and phonologists. $R$ package version 1.0-7., 2016.

[19] A.|R.|Bradlow, G.|M.|Torretta and D.|B.|Pisoni, "Intelligibility of normal speech I: Global and fine-grained acoustic-phonetic talker characteristics", Speech Communication 20, pp. 255-272, 1996.

[20] J. Kirby, Praatdet: Praat-based tools for EGG analysis. (v. 0.1.1), 2017. https://doi.org/10.5281/zenodo.1117189.

[21] A. Michaud and L. N. Thi, 2007. Peakdet. MatLab script. https://github.com/covarep/covarep/tree/master/glottalsource/egg /peakdet.
[22] P. Boersma, "Accurate short-term analysis of the fundamental frequency and the harmonics-to-noise ratio of a sampled sound", in Proceedings of the Institute of Phonetic Sciences 17 University of Amsterdam, pp. 97-110, 1993.

[23] D. M. Howard, "Variation of Electrolaryngographically Derived Closed Quotient for Trained and Untrained Adult Female Singers", Log Phon Vocol 9. (2), pp. 163-172, 1995.

[24] A. Kuznetsova, P. B. Brockhoff and R. H. B. Christensen, "ImerTest Package: Tests in Linear Mixed Effects Models", Journal of Statistical Software 82 (13), pp. 1-26. 2017. http://doi.org/10.18637/jss.v082.i13.

[25] R Core Team, $R$ : A language and environment for statistical computing. R Foundation for Statistical Computing, Vienna, Austria. 2017. https://www.R-project.org/. 